This item was submitted to Loughborough's Research Repository by the author.

Items in Figshare are protected by copyright, with all rights reserved, unless otherwise indicated.

\title{
A comparison of muscle stiffness and musculoarticular stiffness of the knee joint in young athletic males and females
}

PLEASE CITE THE PUBLISHED VERSION

http://dx.doi.org/10.1016/j.jelekin.2015.03.003

\section{PUBLISHER}

(C) Elsevier Ltd.

VERSION

AM (Accepted Manuscript)

\section{PUBLISHER STATEMENT}

This work is made available according to the conditions of the Creative Commons Attribution-NonCommercialNoDerivatives 4.0 International (CC BY-NC-ND 4.0) licence. Full details of this licence are available at: https://creativecommons.org/licenses/by-nc-nd/4.0/

\section{LICENCE}

CC BY-NC-ND 4.0

\section{REPOSITORY RECORD}

Wang, Dan, Giuseppe De Vito, Massimiliano Ditroilo, Daniel Tik-Pui Fong, and Eamonn Delahunt. 2019. "A Comparison of Muscle Stiffness and Musculoarticular Stiffness of the Knee Joint in Young Athletic Males and Females". figshare. https://hdl.handle.net/2134/20621. 


\section{Elsevier Editorial System(tm) for Journal of Electromyography and Kinesiology}

Manuscript Draft

Manuscript Number: JEK-D-14-00299R1

Title: A comparison of muscle stiffness and musculoarticular stiffness of the knee joint in young athletic males and females

Article Type: Research Paper (max. 5,000 words)

Keywords: Knee joint [MeSH]; Quadriceps muscle [MeSH]; Neuromuscular monitoring [MeSH]; Athletic injuries $[\mathrm{MeSH}]$

Corresponding Author: Ms. Dan Wang, Master

Corresponding Author's Institution:

First Author: Dan Wang, Master

Order of Authors: Dan Wang, Master; Giuseppe De Vito; Massimiliano Ditroilo; Daniel Fong; Eamonn Delahunt

Abstract: The objective of this study was to investigate the gender-specific differences in peak torque (PT), muscle stiffness (MS) and musculoarticular stiffness (MAS) of the knee joints in a young active population. Twenty-two male and twenty-two female recreational athletes participated. Peak torque of the knee joint extensor musculature was assessed on an isokinetic dynamometer, MS of the vastus lateralis (VL) muscle was measured in both relaxed and contracted conditions, and knee joint MAS was quantified using the free oscillation technique. Significant gender differences were observed for all dependent variables. Females demonstrated less normalized peak torque (mean difference (MD) $=0.4$ $\mathrm{Nm} / \mathrm{kg}, \mathrm{p}=0.005, \mathrm{\eta} 2=0.17)$, relaxed MS (MD $=94.2 \mathrm{~N} / \mathrm{m}, \mathrm{p}<.001, \mathrm{\eta} 2=0.53)$, contracted MS (MD = $162.7 \mathrm{~N} / \mathrm{m}, \mathrm{p}<.001, \mathrm{y} 2=0.53)$ and MAS $(\mathrm{MD}=422.1 \mathrm{~N} / \mathrm{m}, \mathrm{p}<.001, \mathrm{y} 2=0.23)$ than males. MAS increased linearly with the external load in both genders with males demonstrating a significantly higher slope $(p=0.019)$ than females. The observed differences outlined above may contribute to the higher knee joint injury incidence and prevalence in females when compared to males. 
Title: A comparison of muscle stiffness and musculoarticular stiffness of the knee joint in young athletic males and females

Authors:

1. Dan Wang ${ }^{\mathrm{a}, \mathrm{b}}$

2. Giuseppe De Vito ${ }^{\mathrm{a}, \mathrm{c}}$

3. Massimiliano Ditroilo ${ }^{\mathrm{d}}$

4. Daniel T.P. Fong ${ }^{\mathrm{e}}$

5. Eamonn Delahunt ${ }^{\mathrm{a}, \mathrm{c}}$

Author Affiliations:

${ }^{a}$ School of Public Health, Physiotherapy and Population Science, University College Dublin, Health Sciences Centre, Belfield, Dublin 4, Ireland

${ }^{\mathrm{b}}$ The NO. 2 Clinical Medicine School, Nanjing University of Chinese Medicine, Nanjing, Jiang Su Province, China

${ }^{\mathrm{c}}$ Institute for Sport and Health, University College Dublin, Dublin, Ireland

${ }^{\mathrm{d}}$ Department of Sport, Health \& Exercise Science, Faculty of Science \& Engineering, University of Hull, England

${ }^{\mathrm{e}}$ School of Sport, Exercise and Health Sciences, Loughborough University, Loughborough, Leicestershire, United Kingdom, LE11 3TU

Corresponding Author:

Dan Wang 
School of Public Health, Physiotherapy and Population Science, University College Dublin, Health Sciences Centre, Belfield, Dublin 4, Ireland

EMAIL: dan.wang@ucdconnect.ie

TEL: 0035317166671 (c/o Dr Eamonn Delahunt) 


\begin{abstract}
:
The objective of this study was to investigate the gender-specific differences in peak torque (PT), muscle stiffness (MS) and musculoarticular stiffness (MAS) of the knee joints in a young active population. Twenty-two male and twenty-two female recreational athletes participated. Peak torque of the knee joint extensor musculature was assessed on an isokinetic dynamometer, MS of the vastus lateralis (VL) muscle was measured in both relaxed and contracted conditions, and knee joint MAS was quantified using the free oscillation technique. Significant gender differences were observed for all dependent variables. Females demonstrated less normalized peak torque $\left(\right.$ mean difference $\left.(M D)=0.4 \mathrm{Nm} / \mathrm{kg}, \mathrm{p}=0.005, \mathrm{\eta}^{2}=0.17\right)$, relaxed $\mathrm{MS}(\mathrm{MD}=94.2$ $\left.\mathrm{N} / \mathrm{m}, \mathrm{p}<.001, \mathrm{y}^{2}=0.53\right)$, contracted MS $\left(\mathrm{MD}=162.7 \mathrm{~N} / \mathrm{m}, \mathrm{p}<.001, \mathrm{y}^{2}=0.53\right)$ and MAS $(\mathrm{MD}=$ 422.1 N/m, $\mathrm{p}<.001, \mathrm{y}^{2}=0.23$ ) than males. MAS increased linearly with the external load in both genders with males demonstrating a significantly higher slope $(\mathrm{p}=0.019)$ than females. It is hypothesized that $t$ The observed differences outlined above may contribute to the higher knee joint injury incidence and prevalence in females when compared to males.
\end{abstract}




\section{Introduction}

2 Epidemiological research has reported that female athletes have an increased risk of

3 lower limb musculoskeletal sports related injuries when compared to their male

4 counterparts (Jones et al., 1993, Messina et al., 1999). This observation is particularly

5 relevant in relation to anterior cruciate ligament (ACL) injuries and patellofemoral

6 pain (PFP). Female soccer players have been reported to have a 2-3 times higher risk

7 of ACL injuries when compared to males (Walden et al., 2011)-_; This is also seen in female athletes-in other high velocity, intermittent sports such as basketball and volleyball (Hewett, 2000). PFP is a prevalent lower limb musculoskeletal disorder, observed in young, physically active female athletes (Heintjes et al., 2003, Natri et al., 1998), and is associated with reduced participation in field and court based sports.

Furthermore, it may precipitate the onset of patellofemoral osteoarthritis (Utting et al., 2005), as well as being potentially linked to non-contact ACL injury risk (Myer et al., 2014).

Factors that are thought to contribute to gender differences in the incidence and prevalence of knee joint injuries include; differences in the mechanical properties of the knee joint ligaments, knee joint kinematics during landing, cutting and pivoting, as well as skeletal alignment (Bonci, 1999, Harner et al., 1994, Rosene and Fogarty, 1999). During sport related activities, joint loads increase and knee joint stability is dependent upon activation of the dynamic muscular constraint system, aimed at protecting joints against injury. Kim et al. (Kim et al., 2011) summarized from 
previous studies that co-contraction of agonist and antagonist muscles is important for joint stabilization during dynamic movement; the amount of co-contraction could significantly influence the resultant torque at the knee joint . Billot et al. indicated that agonist-antagonist muscles have a common descending drive control (Billot et al., 2014). Imbalance of quadriceps and hamstring strength (hamstring/quadriceps ratio < 0.6) has been reported as a contributing factor to non-contact knee injuries (Kim et al., 2011). Furthermore, neuromuscular imbalance of decreased hamstring activation relative to quadriceps activation is also well documented as a risk factor for ACL injury (Alentorn-Geli et al., 2009). The role of hamstring muscles during landing or $\underline{\text { cutting is to provide a counterbalancing force to resist the relatively higher quadriceps }}$ force; $\mathrm{hHigher}$ quadriceps muscle activity and altered co-activation patterns in females have been inferred to change the knee joint loads and thereby increase their risk for knee injury (Krishnan et al., 2009). In this context, strength is only one component of injury mechanism; neuromuscular function is actually the primary contributor to the higher risk of non-contact lower limbs injuries in females when compared to males. In contrast, stiffness is a more comprehensive variable which represents the shock absorption characteristics of an individual muscle-tendon unit, joint, or system (Watsford et al., 2010). - Indeed, muscle stiffness is a primary control wariable related to $\mathrm{k}$ Knee joint stability is mainly determined by muscle stiffness (Needle et al., 2014). Additionally, stiffness is a primary determinant of the sheck

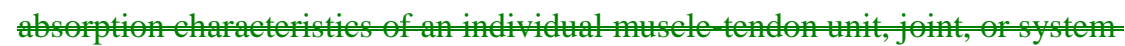
(Watsford al., 2010).A recent consensus paper published by Shultz and colleagues 
45 (Shultz et al., 2012) advocated that further insight into the dynamic-restraint systems

46 of the knee joint beyond absolute strength is are required to understand more

47 comprehensively the potential mechanisms associated with the observed gender

48 disparity in knee joint injuries amongst athletes, with the authors recommending that

49 further research regarding knee joint stiffness is warranted.

50

51 Musculoarticular stiffness (MAS), assessed with the free-oscillation technique, is a

52 comprehensive measurement incorporating the stiffness of the muscle-tendon unit,

53 surrounding articular surfaces, ligaments, and skin. The same technique can be

54 applied to a single muscle using a specific device, thus obtaining a more localized

55

56

57

58

59

60

61

62

63

64

65 measurement of muscle stiffness (MS) than MAS evaluation in joint. It has been advocated that some level of stiffness is beneficial to enhance athletic performance, however too much or too little stiffness may increase the risk of injury (Butler et al, 2003). Further, whilst an elevated level of stiffness appears to be beneficial for rapid $\underline{\text { stretch-shortening cycle (SSC) movements, during relatively slow SSC movements a }}$ more compliant structure can better utilize the eccentric pre-stretch and cushion the impact (Pruyn et al, 2014). That's why MS and MAS have the potential to play crucial roles in neuromuscular control of joint stability, injury prevention and athletic performance (Ditroilo et al., 2012, Ditroilo et al., 2011b). The level of stiffness eontributes to the ability to attenuate excessive external forces, which is why MS and MAS have the potential to play crucial roles in neuromuscular control of joint
Formatted: Font: (Default) Times New Roman, $12 \mathrm{pt}$

Formatted: Font: (Default) Times New Roman, $12 \mathrm{pt}$

Formatted: Font: (Default) Times New Roman, 12 pt

Formatted: Font: (Default) Times New Roman, 12 pt

Formatted: Font: (Default) Times New Roman, 12 pt 
69 To the present authors knowledge, no studies to date have concomitantly measured

70 and compared knee joint MAS and quadriceps MS in male and female recreational

71 athletes. In the present study, $\vee \underline{V}$ astus lateralis (VL) was utilized as representative of

\section{Methods}

\section{Participants}

81

82

83

85

86

87 $63.0 \pm 12.0 \mathrm{~kg}, \mathrm{BMI}=23.1 \pm 3.5 \mathrm{~kg} / \mathrm{m}^{2}$ ) volunteered to participate. The study

Twenty-two male (age $=26.7 \pm 2.6$ years, height $\underline{\text { stature }}=1.77 .2 \pm \underline{0.06} .6 \underline{6 \mathrm{fm}}$, body $\underline{\epsilon}$ mass $\left.=72.6 \pm 9.1 \mathrm{~kg}, \mathrm{BMI}=23.1 \pm 2.4 \mathrm{~kg} / \mathrm{m}^{2}\right)$ and twenty-two female recreational

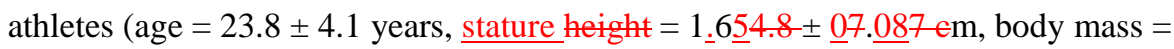
protocol was approved by the University Human Research Ethics Committee, and all participants signed consent forms. The specific inclusion criteria were: (1) recreational athletes who participated in organized sports ; (2) aged: 18-35 years; (3) 
89 (assessed via skinfold thickness ) were deemed acceptable (Ho-Pham et al., 2011));

90 (4) no recent significant soft-tissue injury to the lower limbs in the last 6 months; (5)

91 no reported medical condition that could influence performance. Furthermore,

92 participants were also screened using a medical history questionnaire (Ditroilo et al.,

93 2011a) and the Physical Activity Readiness Questionnaire form.

94

\section{Study design}

Each participant was required to visit the laboratory on one occasion and undergo the following evaluations: (1) peak torque (PT) testing of their right knee joint extensor musculature; (2) relaxed MS testing of their right VL; (3) contracted MS testing of their right VL; (4) contracted MAS testing of their right knee joint.

\section{Peak Torque (PT)}

Each participant underwent PT testing of their right knee joint extensor musculature on a dynamometer (Bodymax Fitness, Clydebank, UK). The participant was seated on the dynamometer with their; hip flexed at $105^{\circ}$ and their right knee flexed at $80^{\circ}$ (where full extension represents $0^{\circ}$ ) (Ditroilo et al., 2012), with the lateral femoral condyle aligned with the axis of the dynamometer. The force transmission point was a bar that was positioned anteriorly to the participant's lateral malleolus. The machine was equipped with a load cell (Leane International, Parma, Italy, measurement range: 0-500 kg, output: $2.00 \mathrm{mV} / \mathrm{V}$ ) applied in series with the plane of force application. 
The load cell was secured to the leg-extension machine with a chain. This prevented

movements of the bar and therefore allowed an isometric contraction when the

participant attempted to extend their leg. Participants were stabilized with straps at the pelvis to avoid movements towards hip extension during the test. Furthermore, to minimize any contribution from the upper body, participants were required to cross their hands across their body throughout. After familiarization with the procedures, participants were instructed to produce a maximum voluntary isometric contraction (MVIC) of their knee joint extensor musculature, as quickly as possible for approximately 3 seconds. Each participant was required to perform three MVICs, with the highest value recorded being used to determine the load with which MAS was assessed. During performance of each MVIC, strong verbal encouragement and visual target stimulation were provided to motivate maximal contraction. The force signal was sampled at $1000 \mathrm{~Hz}$ and stored on a PC using a 16 bit A/D converter data acquisition system (Biopac Systems, Inc. Goleta, CA, USA). Prior to data analysis, the signal was filtered using a 5-ms moving average. The force signal was then multiplied by the individual lever arm length to convert it into torque $(\mathrm{Nm})$. The highest torque value was identified as PT, which was normalized to body mass of each individual (Pincivero et al., 2003) for further analysis.

\section{Muscle stiffness (MS)}

MS of the VL muscle was measured using a device incorporating a probe and an accelerometer (Myometer, Myoton-3, Müomeetria AS, Tallinn, Estonia) sampled at 
$3200 \mathrm{~Hz}$. During MS recordings, the subjects were seated in the same position used for MVIC measurements. The probe was manually positioned perpendicular to the muscle belly with the recording site being $2 / 3$ the distance along a line measured from the anterior superior iliac spine to the midpoint on the lateral side of the patella. The probe was gently lowered onto the muscle belly of the VL with a resultant automatic mechanical impact being delivered to the muscle (duration of $15 \mathrm{~ms}$, a force of 0.3-0.4 $\mathrm{N}$ and a local deformation in the order of a few millimeters) (Ditroilo et al., 2012). The damped natural oscillations were recorded by the accelerometer within the probe giving an instantaneous digital output of the MS. Five consecutive measurements were taken during relaxed (no external load) and contacted (external load $=30 \%$ MVIC) (Fig. 1.) conditions. The average of the five measurements was used for later analysis.

\section{Musculo-articular stiffness (MAS)}

MAS of each participant's right knee joint was measured using a technique previously published by Ditroilo et al., 2012 (Fig. 2.). Participants sat in the same position used previously for MVIC assessments. To quantify submaximal MAS stiffness, the participants were required to support a load corresponding to $30 \%$ of MVIC on the anterior distal portion of their lower leg. An external perturbation of $100-150 \mathrm{~N}$ was applied to the bar by the investigator and the ensuing oscillations were recorded by a uniaxial accelerometer (Crossbow, Milpitsa, CA, USA) attached to the distal end of the lever arm of the leg-extension dynamometer. Accelerometer data were sampled at 
$1000 \mathrm{~Hz}$ and recorded on a personal computer using a 16-bit A/D converter. A

155 Butterworth low-pass filter (third order) with a cutoff frequency of $4 \mathrm{~Hz}$ was used to

156 filter the signal. Each participant completed five MAS trials separated by a 1-min rest

157 period, with the average of the three trials being used for analysis. Considering the

158 positive relationship between the active joint stiffness and the applied load, stiffness

159 gradient, defined as the ratio of the two parameters, was subsequently calculated

160 afterwards and utilized as an independent variable in the statistical analysis

161 (Gardner-Morse et al., 1995).

162

163 Statistical Analysis

164 Independent samples $t$-tests (two tailed) were undertaken to investigate differences

165 between males and females on the following four dependent variables: (1) PTpeak torque; (2) relaxed MS; (3) contracted MS; (4) MAS. Statistical analyses were

167 conducted in IBM SPSS Statistics 20 (IBM Ireland Ltd, Dublin, Ireland). To account

168 for the number of analyses undertaken, statistical significance was set a priori at $\mathrm{p} \leq$

1690.0125 (Bonferroni adjustment). Furthermore, a one-way between-groups analysis of

170 covariance (ANCOVA) was conducted to investigate differences in stiffness gradient

171 across genders with the external load as the covariate; the level of significance was set

172 at $\mathrm{p}<0.05$.

173

174 Results 
175 A significant difference was observed between males and females in; normalized

176 PTpeak torque (PTpeak torque/ body mass) (males $2.8 \pm 0.4 \mathrm{Nm} / \mathrm{kg}$, females $2.4 \pm 0.4$

$177 \mathrm{Nm} / \mathrm{kg}$ (Fig. 3.); t $(42)=2.96, \mathrm{p}=0.005)$, relaxed MS (males $364.4 \pm 52.0 \mathrm{~N} / \mathrm{m}$,

178 females $270.3 \pm 33.3 \mathrm{~N} / \mathrm{m}$ (Fig. 4.); $\mathrm{t}(42)=6.90, \mathrm{p}<.001)$, contracted MS (males

$179495.1 \pm 71.0 \mathrm{~N} / \mathrm{m}$, females $332.3 \pm 85.4 \mathrm{~N} / \mathrm{m}($ Fig. 5.$) ; \mathrm{t}(42)=6.9, \mathrm{p}<.001)$ and

180 MAS (males $1450.1 \pm 508.0 \mathrm{~N} / \mathrm{m}$, females $1028.0 \pm 227.3 \mathrm{~N} / \mathrm{m}$ (Fig. 6.); $(42)=$

$1813.55, \mathrm{p}<.001)$.

182

183

The magnitude of the difference in means was also large for; normalized peak torque

184

$\underline{\mathrm{PT}}\left(\right.$ mean difference $(\mathrm{MD})=2.3 \mathrm{Nm} / \mathrm{kg}, 95 \% \mathrm{CI}: 0.1$ to $\left.0.6, \mathrm{y}^{2}=0.17\right)$, relaxed $\mathrm{MS}$

$185\left(\mathrm{MD}=94.2 \mathrm{~N} / \mathrm{m}, 95 \% \mathrm{CI}: 66.6\right.$ to $\left.121.7 \mathrm{\eta}^{2}=0.53\right)$, contracted $\mathrm{MS}(\mathrm{MD}=162.7 \mathrm{~N} / \mathrm{m}$,

95\% CI: 114.9 to $\left.210.5, \mathrm{y}^{2}=0.53\right)$ and MAS (MD $=422.1 \mathrm{~N} / \mathrm{m}, 95 \% \mathrm{CI}: 179.5$ to

$\left.187 \quad 664.8 \mathrm{y}^{2}=0.23\right)$

188

189

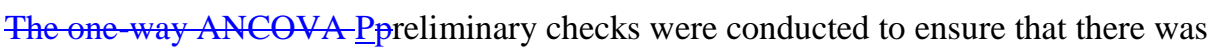

190 no violation of the assumptions of normality, linearity, homogeneity of variances and

191 regression slopes, and reliable measurement of the covariate before one-way

192

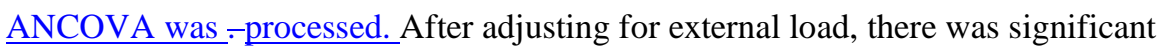
difference for MAS between the two groups, $F(1,42)=6.02, p=0.019$, with males having a steeper stiffness gradient slope than females (Males, $\mathrm{Y}=36.92 \mathrm{X}-786.51, \mathrm{r}^{2}=$ 0.80; Females, $\mathrm{Y}=18.32 \mathrm{X}+224.49, \mathrm{r}^{2}=0.33$ ). (Fig. 7.). 


\section{Discussion} 1992), as well as intrinsic properties (actin-myosin cross-bridge, and protein titin) for instance suggested that higher hamstring stiffness values in males were ascribed to

This investigation aimed to identify whether differences in the stiffness characteristics of the knee joint exist between young recreationally athletic males and females. Tothe best of the authors' knowledge, this is the first study to concurrently measure MSof the VL and MAS of the knee joint (extensor) in young recreational athletes. The primary findings were that females have lower relaxed and contracted MS of the VL and were characterized by lower knee joint MAS, which are important mechanisms underlying gender disparity. It is possible that these observed stiffness discrepanciesacross genders may contribute to higher rates of knee injury incidence and prevalenceebserved in female athletes.

MS is a localized evaluation of the muscle's ability to resist external load. It is influenced by geometry (physiological cross-sectional area, PCSA) (Foure et al., 2012) and hence muscle mass (muscle mass $=$ PCSA*fiber length* $\rho$ ) (Narici et al., (Proske and Morgan, 1999, Wuet al, 2000). Therefore, gender differences in relaxed MS could be attributable to the fact that males have a larger PCSA, greatermore muscle mass and therebythus a greater amountmore of muscle fiber cross-bridges (Blackburn et al., 2004) and titin than females. Gajdosik et al. (Gajdosik et al., 1990)
Formatted: Not Highlight

Formatted: Not Highlight Formatted: Not Highlight

Formatted: Not Highlight greater muscle mass compared to their female, whilst Blackburncounterparts. 
be responsible for observed gender differences in passive knee flexor stiffness ${ }_{2}$ -

fFurthermore, increased muscle mass in males implies more passive connective tissue, and hence a greater number of collagen fibers for lengthening resistance when compared to these infemales, leading to increased passive stiffness (Blackburn et al.,

223 2004). In addition, in contracted muscles, the amount of cross-bridges formed should

224 also be considered, as contracted MS has been found to be proportional to contractile 225 forces in muscle (Needle et al., 2014). Previous studyies hasłe shown that males are stronger than females (Hannah et al., 2012, Wojtys et al., 2002a), a finding also

227 confirmed by the present study, whereby males produced significantly higher normalized PTpeak torques values compared to females $(2.8 \pm 0.4 \mathrm{Nm} / \mathrm{kg}$ vs $2.4 \pm 0.4$

$229 \mathrm{Nm} / \mathrm{kg})$.

231 Males were also found to have greater MAS compared to females, which is consistent

232 with conclusions of a previous study (Blackburn et al., 2009). Sinkjaer et al. (Sinkjaer

233 et al., 1988) divided MAS into two parts: the intrinsic component (deformation and

234 breakdown of actin-myosin filament cross-bridges) and the reflexive component

235 (occurs after the establishment of intrinsic portions during rapid muscle stretches).

236 The intrinsic component increases linearly with background torque (pre-activation)

237 (Mrachacz-Kersting and Sinkjaer, 2003) which is the external stretch on quadriceps;

238 whilst the reflexive component is integrated by the central nervous system-(CNS), and 239 accounts for approximately $50 \%$ of the total stiffness (Hinsey, 2011). Muscle

240 contraction plays an essential role in joint stiffness (Needle_et al., 2014), leading to a 
241 2-4 times increase in knee joint stability (Markolf et al., 1976). Furthermore, studies

242 have reported that active joint stiffness is proportional to the force generated by

243 muscles (Morgan, 1977, Mørganet al., 1978). Thus, factors related to muscle force

244 production, such as geometric mechanisms (Granata et al., 2002b), cross-bridge

245 mechanics and material qualities (Hinsey, 2011) are promising explanations for the

246 gender differences in joint stiffness found in the current investigation.

247

248 In addition to the aforementioned mechanisms, knee joint stiffness properties can also

249 be influenced by hormones, specifically free testosterone (FT) (Bell et al., 2012,

250 Granataet al., 2002b). An early study showed that when compared to females, male

251 adults possess approximately 7-8 times more FT (Southren et al., 1965). It has been

252 observed that an inverse relationship exists between FT and time to $50 \%$ peak torque;

253 with shorter time to $50 \%$ peak torque $\underline{\mathrm{PT}}$ being more advantageous to overall joint

254 stability (Bell et al., 2012, Blackburn et al., 2009). Bell et al., 2012, have reported that

255 a negative relationship exists between estrogen and MAS, offering some explanation

256 for the lower MAS observed in females. We hypothesize that this is the case for the

257 present study although no experimental measurements were carried out.

258

259 Stiffness gradient is an essential tool to describe active stiffness characteristics. The

260 results of the current study demonstrated a significantly higher stiffness gradient in

261 males in comparison to females, indicating that when an applied moment increases,

262 joint stiffness subsequently increases, and males manifest a higher degree of increased 

present study could help explain the higher risk of lower-limb injuries in females. It

279 could also point out one possible solution for preventing injuries in females and males. Training; such as weight (Kubo et al., 2007), isometric (Burgess et al., 2007), eccentric (Poussen et al., 1990), and plyometric training (Spurrs et al., 2003) have all

stiffness. Therefore, it is reasonable to assume that males are characterized by greater ability to resist external loads which has implications for injury risk in females. The observed difference in stiffness gradient between males and females is also supported by the findings of Granata et al., 2002b which reported that stiffness increased with the external load, and there was a significant difference in slope of linear regressions between stiffness and applied load with females demonstrating a reduced regression slope.

Joint stiffness parameters are integrated by the CNS internally and exhibit mechanical characteristics externally. As a consequence, it is an important variable capable of comprehensively representing joint stability and muscle performance. A higher degree of stiffness may provide more resistance to external load during functional performance and hence protect joints from musculoskeletal injury (Granata et al., 2002a). A decrease in joint stiffness or MS reduces structures' capacity to resist external applied loads, and hence the gender differences in stiffness observed in the been suggested to be beneficial for stiffness augmentation. In the future, it is important to investigate what kind of training is best for stiffness enhancement. 
Limitations of this study include; not measuring the participants' testosterone and

286 estrogen levels, and also not controlling females' menstrual cycle due to time and

287 financial limits. The effect of menstrual cycle hormone fluctuations on stiffness

288 properties and the injury occurrence is still controversial. The study of Eiling et al.

289 (Eiling et al., 2007) indicated significant effect of estrogen levels on

290 musculotendinous stiffness at the time of ovulation when compared to the menstrual

291 and follicular phase; and more acute ACL tears were reported in females during

292 mid-cycle by Wojtys et al. (Wojtys et al., 2002b). However, Bryant et al. (Bryant et

293 al., 2011) attested no significant leg stiffness difference between non-MOCP

294 (monophasic oral contraceptive pill) and MOCP users.

\section{Conclusions}

297 Gender differences exist in the knee joint stiffness properties of young active populations. Females exhibit a lower level of MS and MAS when compared to males. The mechanism explaining this difference is still unknown, but neuromuscular control and muscle volume differences may affect MS and MAS. This study's results may provide some interpretation as to why females incur more knee injuries than their male counterparts. Investigation of optimal training programmes for the augmentation of MS and MAS should be of interest in future. 
307 Council (CSC).

310 1. Alentorn-Geli E, Myer GD, Silvers HJ, Samitier G, Romero D, Lazaro-Haro C,

311 Cugat R. Preention of non-contact anterior cruciate ligament injuries in soccer players. Part 1: Mechanisms of injury and underlying risk factors. Knee surgery, sports traumjatology, arthroscopy. 2009;17(7):705-29. Padua DA. Estrogen and muscle stiffness have a negative relationship in females. Knee surgery, sports traumatology, arthroscopy. 2012;20(2):361-7. $\underline{\text { co-contraction responsible for the decline in maximal knee joint torque in older }}$ males? AGE. 2014;36(2):899-910.

321 hamstring neuromechanical properties between healthy males and females and

322 the influence of musculotendinous stiffness. Journal of electromyography and

$323 \quad$ kinesiology. 2009;19(5):e362-9.

324 3.5. Blackburn JT, Riemann BL, Padua DA, Guskiewicz KM. Sex comparison of extensibility, passive, and active stiffness of the knee flexors. Clinical biomechanics. 2004;19(1):36-43. 
327 4.6. Bonci CM. Assessment and evaluation of predisposing factors to anterior cruciate 328 ligament injury. Journal of athletic training. 1999;34(2):155-64.

329 7._Bryant AL, Crossley KM, Bartold S, Hohmann E, Clark RA. Estrogen-induced 330 effects on the neuro-mechanics of hopping in humans. European journal of

$331 \quad$ applied physiology. 2011;111(2):245-52.

332 5.8. Butler RJ, Crowell HP, Davis IM. Lower extremity sitffness: implications for

333 performance and injury. Clinical biomechanics. 2003; 8(6):511-7.

334

335

eonditioning research. 2007:21(3):986-9.

337 7.9. Cafarelli E. Peripheral and central inputs to the effort sense during cycling

338 exercise. European journal of applied physiology and occupational physiology.

$339 \quad 1977 ; 37(3): 181-9$.

$340 \mid 8.10$. Ditroilo M, Cully L, Boreham CA, De Vito G. Assessment of

341 musculo-articular and muscle stiffness in young and older men. Muscle \& nerve.

$342 \quad 2012 ; 46(4): 559-65$.

343 9.11. Ditroilo M, Watsford M, Fernandez-Pena E, D'Amen G, Lucertini F, De Vito

344 G. Effects of fatigue on muscle stiffness and intermittent sprinting during cycling.

$345 \quad$ Medicine and science in sports and exercise. 2011a;43(5):837-45.

$346 \mid$ 10.12. Ditroilo M, Watsford M, Murphy A, De Vito G. Assessing

347 Musculo-Articular Stiffness Using Free Oscillations Theory, Measurement and

Analysis. Sports medicine. 2011b;41(12):1019-32.

\begin{tabular}{l} 
Formatted: Font: (Default) Times New \\
Roman, $12 \mathrm{pt}$ \\
$\begin{array}{l}\text { Formatted: Normal, No bullets or } \\
\text { numbering }\end{array}$ \\
$\begin{array}{l}\text { Formatted: Font: (Default) Times New } \\
\text { Roman, } 12 \mathrm{pt}\end{array}$ \\
\hline
\end{tabular}
Roman, $12 \mathrm{pt}$ 
349

350 menstrual-cycle hormone fluctuations on musculotendinous stiffness and knee

351 joint laxity. Knee surgery, sports traumatology, arthroscopy. 2007;15(2):126-32.

$352 \mid$ 12.14. Foure A, Cornu C, McNair PJ, Nordez A. Gender differences in both active

353 and passive parts of the plantar flexors series elastic component stiffness and

354 geometrical parameters of the muscle-tendon complex. Journal of orthopaedic

355 research. 2012;30(5):707-12.

356 13.15. Gajdosik RL, Giuliani CA, Bohannon RW. Passive compliance and length of 357 the hamstring muscles of healthy men anc women. Clinical biomechanics.

$358 \quad 1990 ; 5(1): 23-9$

359 |14.16. Gardner-Morse M, Stokes IA, Laible JP. Role of muscles in lumbar spine

360 stability in maximum extension efforts. Journal of orthopaedic research.

$361 \quad 1995 ; 13(5): 802-8$.

362 15.17. Granata KP, Padua DA, Wilson SE. Gender differences in active

363 musculoskeletal stiffness. Part II. Quantification of leg stiffness during functional

364 hopping tasks. Journal of electromyography and kinesiology.

$3652002 \mathrm{a} ; 12(2): 127-35$.

$366 \mid$ 16.18. Granata KP, Wilson SE, Padua DA. Gender differences in active

367 musculoskeletal stiffness. Part I. Quantification in controlled measurements of

368 knee joint dynamics. Journal of electromyography and kinesiology.

369 2002b;12(2):119-26. 

19.20. Heintjes E, Berger MY, Bierma-Zeinstra SM, Bernsen RM, Verhaar JA,

377 Koes BW. Exercise therapy for patellofemoral pain syndrome. The Cochrane database of systematic reviews. 2003(4):CD003472. 20.21. Hewett TE. Neuromuscular and hormonal factors associated with knee

21.-22. Hinsey ML. Comparison of reactive knee stiffening strategies between sexes.

17. Hannah R, Minshull C, Buckthorpe MW, Folland JP. Explosive neuromuscular

performance of males versus females. Experimental physiology.

$2012 ; 97(5): 61829$.

18.19. Harner CD, Paulos LE, Greenwald AE, Rosenberg TD, Cooley VC. Detailed Analysis of Patients with Bilateral Anterior Cruciate Ligament Injuries. American journal of sports medicine. 1994;22(1):37-43.

injuries in female athletes - Strategies for intervention. Sports medicine. $2000 ; 29(5): 313-27$.

2011. Masters Thesis, University of Delaware.

23. Ho-Pham LT, Campbell LV, Nguyen TV. More on body fat cutoff points. Mayo Clinic proceedings. 2011;86(6):584; author reply -5.

24. Jones BH, Bovee MW, Harris JM, Cowan DN. Intrinsic Risk-Factors for Exercise-Related Injuries among Male and Female Army Trainees. American journal of sports medicine. 1993;21(5):705-10.

25. Kim D, Hong JG. Hamstring to quadriceps strength ratio and noncontact leg injuries: A prospective study during one season. Isokinetics and exercise science. 2011; 19(1):1-6.
Formatted: Font: (Default) Times New Roman, $12 \mathrm{pt}$ 
24.26. Krishnan C, Williams GN. Sex difference in quadriceps and hamstrings

EMG-Moment relationships. Medical \& science in sports \& exercise. 2009;

\section{1(8):1652-60.}

25.27. Kubo K, Morimoto M, Komuro T, Yata H, Tsunoda N, Kanehisa H,

Fukunaga T. Effects of plyometric and weight training on muscle-tendon complex and jump performance. Medicine and science in sports and exercise. 2007;39(10):1801-10.

26.28. Markolf KL, Mensch JS, Amstutz HC. Stiffness and laxity of the knee--the contributions of the supporting structures. A quantitative in vitro study. The Journal of bone and joint surgery American volume.

$1976 ; 58(5): 583-94$.

27.29. Messina F, Farney WC, DeLee JC. The incidence of injury in Texas high school basketball. A prospective study among male and female athletes.

American journal of sports medicine. 1999;27(3):294-9.

28.30. Morgan DL. Separation of active and passive components of short-range stiffness of muscle. The American journal of physiology. 1977;232(1):C45-9.

29. Morgan DL, Proske U, Warren D. Measurements of muscle stiffness and the mechanism of elastic storage of energy in hopping kangaroos. The Journal of physiology. 1978;282:253-61.

\subsection{Mrachacz-Kersting N, Sinkjaer T. Reflex and non-reflex torque} responses to stretch of the human knee extensors. Experimental brain research. 2003;151(1):72-81 
31.32. Myer GD, Ford KR, Di Stasi SL, Barber Foss KD, Micheli LJ, Hewett

TE. High knee abduction moments are common risk factors for patellofemoral pain (PFP) and anterior cruciate ligament (ACL) injury in girls: Is PFP itself a predictor for subsequent ACL injury? British journal of sports medicine. 2014. (epub ahead of print)

\subsection{Narici MV, Landoni L, Minetti AE. Assessment of human knee extensor} muscles stress from in vivo physiological cross-sectional area and strength measurements. European journal of applied physiology and occupational physiology. 1992;65(5):438-44.

33.34. Natri A, Kannus P, Jarvinen M. Which factors predict the long-term outcome in chronic patellofemoral pain syndrome? A 7-yr prospective follow-up study. Medicine and science in sports and exercise. 1998;30 (11):1527-77.

34.35. Needle AR, Baumeister J, Kaminski TW, Higginson JS, Farquhar WB, Swanik CB. Neuromechanical coupling in the regulation of muscle tone and joint stiffness. Scandinavian journal of medicine \& science in sports. 2014. (epub ahead of print)

\subsection{Pincivero DM, Gandaio CM, Ito Y. Gender-specific knee extensor} torque, flexor torque, and muscle fatigue responses during maximal effort contractions. European journal of applied physiology. 2003;89(2):134-41. 
36. Pousson M, Van Hoecke J, Goubel F. Changes in elastic characteristics of

human muscle induced by eccentric exercise. Journal of biomechanics.

$1990 ; 23(4): 3438$.

37. Proske U, Morgan DL. Do cross-bridges contribute to the tension during stretch of passive muscle? Journal of muscle research and cell motility.

1999;20(5-6):433-42.

37.38. Pruyn EC, Watsford M, Murphy A. The relationship between

lower-body stiffness and dynamic performance. Applied physiology, nutrition and metabolism. 2014; 39(109): 1144-50.

38.39. Rosene JM, Fogarty TD. Anterior tibial translation in collegiate athletes with normal anterior cruciate ligament integrity. Journal of athletic training. 1999;34(2):93-8.

39.40. Shultz SJ, Schmitz RJ, Benjaminse A, Chaudhari AM, Collins M, Padua DA. ACL Research Retreat VI: An Update on ACL Injury Risk and Prevention. Journal of athletic training. 2012;47(5):591-603.

40.41. Sinkjaer T, Toft E, Andreassen S, Hornemann BC. Muscle stiffness in human ankle dorsiflexors: intrinsic and reflex components. Journal of neurophysiology. 1988;60(3):1110-21.

41.42. Southren AL, Tochimoto S, Carmody NC, Isurugi K. Plasma production rates of testosterone in normal adult men and women and in patients with the syndrome of feminizing testes. Journal of clinical endocrinology \& metabolism 1965;25(11):1441-50. 
42.43. Spurrs RW, Murphy AJ, Watsford ML. The effect of plyometric training on distance running performance. European journal of applied physiology. $2003 ; 89(1): 1-7$.

43.44. Utting MR, Davies G, Newman JH. Is anterior knee pain a predisposing factor to patellofemoral osteoarthritis? The Knee. 2005;12(5):362-5.

44.45. Walden M, Hagglund M, Werner J, Ekstrand J. The epidemiology of anterior cruciate ligament injury in football (soccer): a review of the literature from a gender-related perspective. Knee surgery, sports traumatology, arthroscopy. 2011;19(1):3-10.

45.46. Watsford ML, Murphy AJ, McLachlan KA, Bryant AL, Cameron ML, Crossley KM, Makdissi M. A prospective study of the relationship between lower body stiffness and hamstring injury in professional Australian rules footballers. American journal of sports medicine. 2010;38(10):2058-64. 46.47. Wojtys EM, Ashton-Miller JA, Huston LJ. A gender-related difference in the contribution of the knee musculature to sagittal-plane shear stiffness in subjects with similar knee laxity. The Journal of bone and joint surgery American volume. 2002a;84-A(1):10-6.

\subsection{Wojtys EM, Huston LJ, Boynton MD, Spindler KP, Lindenfeld TN. The} effect of the menstrual cycle on anterior cruciate ligament injuries in women as determined by hormone levels. American journal of sports medicine. $2002 b ; 30(2): 182-8$. 
48. Wu Y, Cazorla O, Labeit D, Labeit S, Granzier H. Changes in titin and eollagen underlie diastolic stiffness diversity of cardiac muscle. Journal of molecular and cellular cardiology. 2000;32(12):215162. 


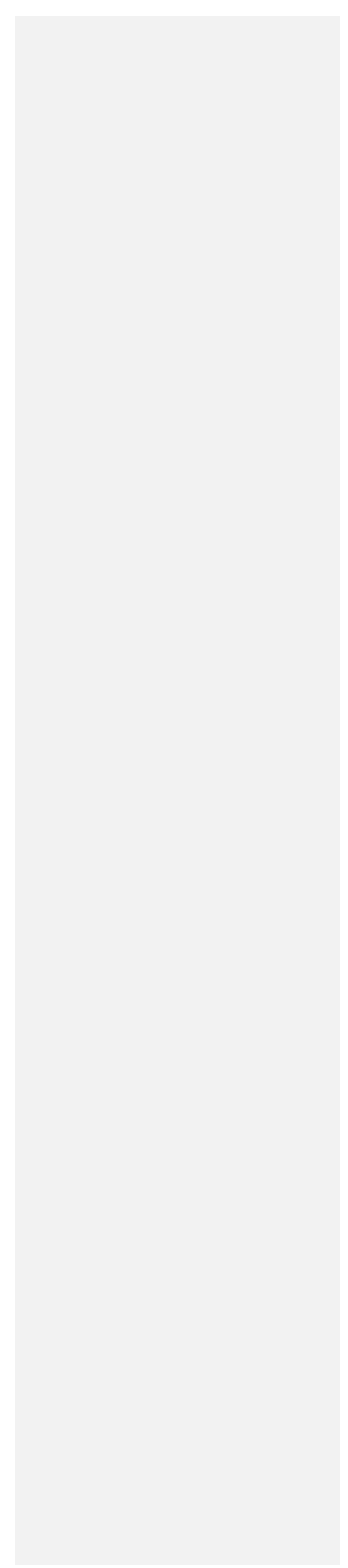




\section{Captions to illustrations}

Fig. 1. Myometer was utilized to evaluate cContracted MS measurement technique. MS = muscle stiffness

Fig. 2. MAS measurement with free oscillation technique. MAS = musculoarticular stiffness

Fig. 3. Comparison of nNormalized peak torque (peak torque/body mass) between males and females (Mean \pm SD (Standard Deviation) $)$.

* indicates statistically significant difference compared to males.

Formatted: Font: (Default) Times New Roman

Fig. 4. Comparison of rRelaxed MS $\underline{\text { between males and females (Mean } \pm \text { SD)}}$. MS = muscle stiffness

* indicates statistically significant difference compared to males.

Fig. 5. Comparison of cContracted MS between males and females (Mean $\underline{ \pm S D})$. MS = muscle stiffness

* indicates statistically significant difference compared to males.

Fig. 6. Comparison of MAS between males and females (Mean $\underline{ \pm S D})$. MAS = musculoarticular stiffness

* indicates statistically significant difference compared to males.

Fig. 7. Relationship between MAS of the knee joint and applied load. MAS = musculoarticular stiffness

MAS increased with applied load in both genders. Linear regressions between stiffness and applied load for the male and female populations are significantly different in slope (Males, $\mathrm{Y}=$ 36.92X-786.51, $\mathrm{r}^{2}=0.80 ;$ Females, $\left.\mathrm{Y}=18.32 \mathrm{X}+224.49, \mathrm{r}^{2}=0.33\right)$. 


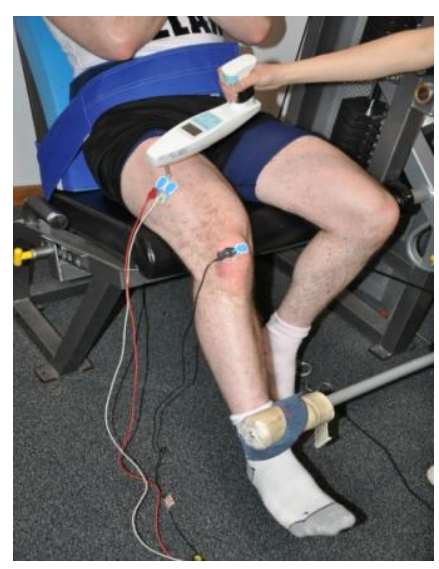




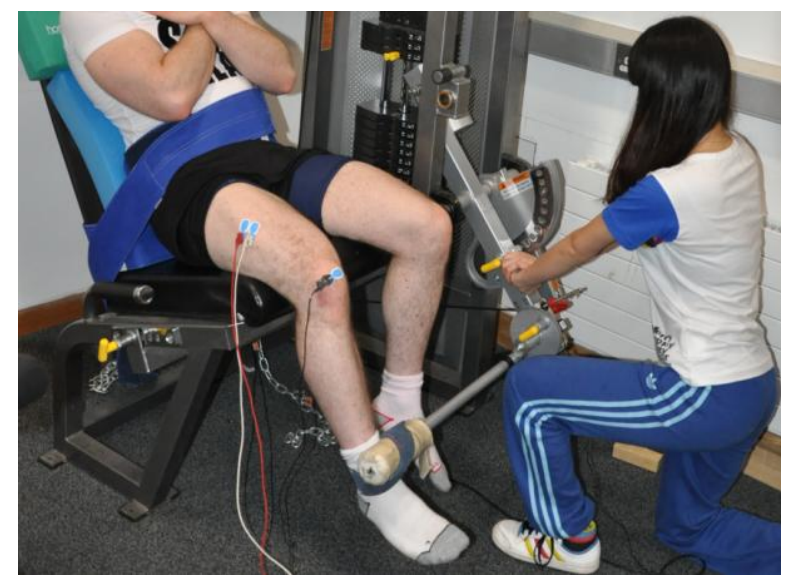




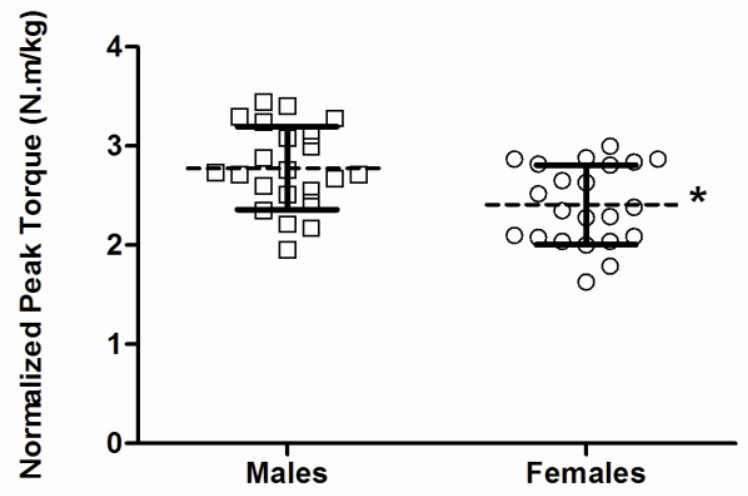




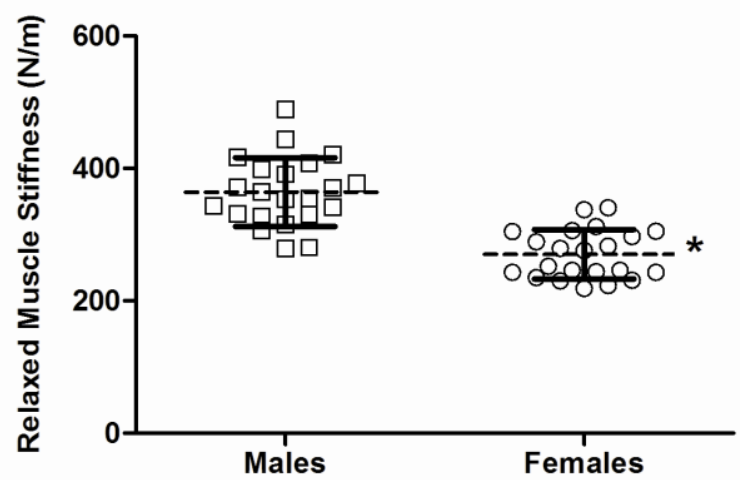




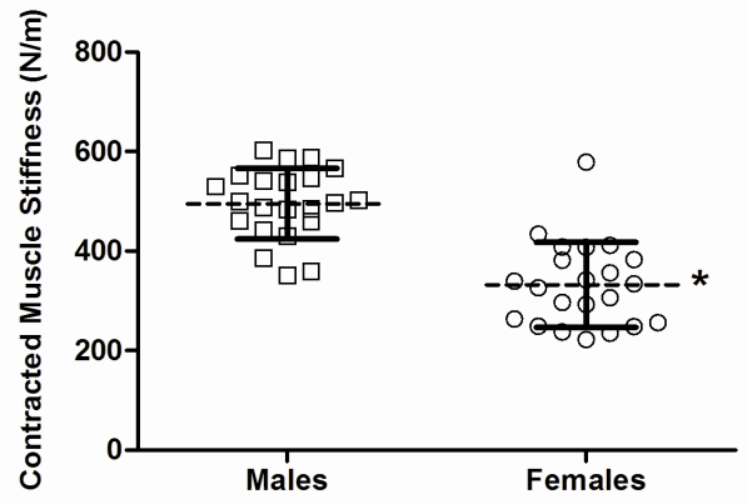

